QNueva Ettinexaxia Revista Digital de OFilosofia ISSN 1850-3578 2013 - Vol. 8 - Número VIII - Resistencia, Chaco, Argentina. Pp. 174 - 196

\title{
G. Deleuze - M. Foucault. Acerca de la relación entre genealogía, arqueología y rizoma como métodos filosóficos
}

\author{
Miriam Lucero \\ Universidad Nacional de San Juan. \\ UNSAM-UNTreF-CONICET (Argentina)
}

Recibido: 19/07/2013

Aceptado: $24 / 08 / 2013$

\section{Resumen}

En este trabajo indagamos las perspectivas metodológicas de G. Deleuze y M. Foucault, y la vinculación que ambos tienen con el concepto nietzscheano de genealogía. Sostenemos como hipótesis que pese a la estrecha vinculación entre sus pensamientos, es el marco de la problemática metodológica donde sus pensamientos adquieren nuevos matices, producto de la apuesta deleuziana por la invención y el lugar privilegiado que en su producción le otorga al arte. Revisaremos para ello, en lo que respecta a Foucault el giro que experimenta su pensamiento entre los análisis arqueológicos y los genealógicos, mientras que en Deleuze analizaremos su método predilecto: el rizoma. Advertimos que la puesta en conjunción de ambos pensamientos desde su perspectiva metodológica puede generar nuevas aristas a la comprensión de ambos autores, y delimitar el carácter políticamente inédito de sus miradas.

Palabras clave: genealogía * arqueología * rizoma * política * método

\section{Summary}

In this paper we investigate the methodological perspectives of G. Deleuze and M. Foucault, and linking both have the Nietzschean concept of genealogy. We maintain the hypothesis that despite the close links between their thoughts, is the framework of the methodological where your thoughts take on new hues, Deleuze product bet by the invention and the privileged place in his art production grants. Check to this, in regard to Foucault turning experiencing their thinking between archaeological and genealogical analysis, while Deleuze discuss your preferred method: the rhizome. We note that the combination of both start from the 
QNueva Ettinexaria Revista Digital de OFilosofla ISSN 1850-3578 2013 - Vol. 8 - Número VIII - Resistencia, Chaco, Argentina. Pp. 174 - 196

methodological perspective thoughts can generate new edges to the understanding of both authors, and define the character of their looks politically unpublished.

Keywords: genealogy * Archaeology * rhizome * policy * method 
Pverea Etinexaxio Revista Digital de OFilosofla ISSN 1850-3578 2013 - Vol. 8 - Número VIII - Resistencia, Chaco, Argentina. Pp. 174 - 196

\section{Introducción}

"Nietzsche dispone de un método de su invención: no hay que contentarse ni con la biografía ni con la bibliografía, hay que alcanzar el punto secreto en el que es la misma cosa una anécdota de la vida y un aforismo del pensamiento". DELEUZE,

Gilles. Lógica del Sentido, p. 140

Tal vez el pensamiento de Gilles Deleuze y Michael Foucault a través de su prodigiosa amistad haya transitado por la experiencia de la que hablara Nietzsche. Quizás hayan construido entre ellos una zona de indiscernibilidad ${ }^{1}$. Acaso podemos experimentarlo en ciertas ocasiones, aquellas en las que ambos recuerdan la obra del otro $^{2}$, pero especialmente cuando revisamos la obra que Gilles Deleuze le dedicara a su amigo luego de su muerte ${ }^{3}$. Allí, se hace muy difícil para nosotros -sus lectores- desentrañar y distinguir el andamiaje conceptual de cada uno, como entidades separadas. Quizás esto se deba a que no hay entre quienes piensan la política en términos de producción una separación tangible entre los enunciados. Por el contrario, la política elaborada por ellos supone la primacía de los otros, del Otro -ese afuera que nos reclama- para pensar entre los intersticios de sus pensamientos. Basta recordar la lucha que entablan juntos -en la que también habría que incluir a Félix Guattari-, en aquellos convulsionados años donde fueron "compañeros de resistencia" ${ }^{4}$ en las calles de París. Lucha efectiva que desarrollaron en los ámbitos teóricos y prácticos, cuando conformaron el G.I.P. (Groupe d'information sur les prisons), pero también a través de la defensa de diferentes movimientos de grupos minoritarios ${ }^{5}$. No podemos olvidar el contexto de Mayo del 68', cuando al mismo tiempo que se exige un nuevo modo de pensar la política, se pone en cuestión las bases sobre la que se había edificado el poder, incluso en la izquierda francesa ${ }^{6}$.

\footnotetext{
${ }^{1}$ Atribuimos a la dupla Deleuze-Foucault la carencia de relación o la nueva forma de relación que instaura Melville a través de Bartleby, el escribiente, según el análisis que sobre él realiza Deleuze. Para quien el personaje desactiva la lógica de los presupuestos e instaura una lógica de la preferencia. (Cfr. DELEUZE, Gilles; AGAMBEN, Giorgio; PARDO, José Luis, Preferiría no hacerlo, Valencia, Pre-textos, 2011, pp. 66-67 y 73

${ }_{2}^{2}$ FOUCAULT, Michael, Defender la sociedad. Buenos Aires. Fondo de Cultura Económica. 2008 pp. 19-20 y FOUCAULT, Michael, La verdad y las formas jurídicas. Barcelona. Gedisa. 2003, pp. 37-38

${ }^{3}$ DELEUZE, Gilles. Foucault. Buenos Aires. Paidós. 2008.

${ }^{4}$ Cabe aclarar que la alianza entre ellos es en sentido figurado, dado que cuando los estudiantes toman las calles de Paris, Foucault está residiendo en Túnez, tal como lo comenta su compañero Daniel Defert en Op. Cit. FOUCAULT, Michael, Defender la sociedad. 2008

${ }^{5}$ La propia lectura retrospectiva que años más tarde realiza Deleuze de este acontecimiento es entendida en términos minoritarios: “En Mayo del 68' ocurrió lo mismo: todos los que lo juzgaban en términos de macropolítica no comprendieron nada del acontecimiento, puesto que algo inasignable huía". DELEUZE, Gilles; GUATTARI, Félix, Mil Mesetas. Valencia, Pre-textos, 2008, p. 221

${ }^{6}$ NAVARRO CASABONA, Alberto, Introducción al pensamiento estético de Gilles Deleuze. Madrid, Tirant lo Blanch, 2010, pp. 130-134
} 
Q Nueva Etinexaxio Revista Digital de OFilosofia ISSN 1850-3578 2013 - Vol. 8 - Número VIII - Resistencia, Chaco, Argentina. Pp. 174 - 196

La complicidad de sus perspectivas coinciden además en lo que respecta a la propuesta metodológica: ambos autores convienen en resaltar la fuerza de la impronta nietzscheana en sus pensamientos. De tal modo, hacen de la genealogía uno de los pilares sobre los que se erige la construcción de sus métodos. Sin embargo, nos resultaría imposible exponer en las páginas que siguen la enorme serie de encuentros y desencuentros que sus filosofas tienen ${ }^{7}$. Por ello, intentaremos circunscribirnos a la cuestión metodológica. En verdad, focalizar en sus respectivos métodos permite advertir matices que inevitablemente los separan y singularizan sus filosofías. En especial, en relación al método predilecto de G. Deleuze, el rizoma, destacamos una cierta reticencia o desacuerdo con el concepto de genealogía, llegándose a afirmar el método rizomático como antigenealogia ${ }^{8}$ Puesto que "el árbol siempre tiene algo de genealógico [...] un método de tipo rizoma sólo puede analizar el lenguaje descentrándolo sobre otras dimensiones y otros registros" ${ }^{\prime \prime}$.

Por otra parte, en el pensamiento de M. Foucault el concepto de genealogía es un mecanismo de comprensión de los acontecimientos, no obstante funciona de manera similar en ciertos estudios de G. Deleuze, cuestión que desarrollaremos en el trascurso del escrito. Va de suyo, que el concepto aquí descripto expresa, en un lenguaje llano el conocido árbol genealógico, que funciona en la tradición popular como modo de recordar nuestra filiación con los ancestros y no tendría relación con el sentido nietzscheano del término. Sin embargo, es sobre este juego de sentido que, suponemos, proponen Deleuze y Guattari un nuevo modo de pensar el método, en relación con el discurso y el poder.

Nos interesa indagar, entonces, las (supuestas) causas de tal distanciamiento con la perspectiva genealógica que ambos extrajeran de F. Nietzsche. La distancia con el análisis genealógico en esta época de su producción intelectual supondría una diferencia ineludible al momento de pensar las relaciones entre ambos autores, y en consecuencia, los separaría en el modo de pensar la verdad y el poder. Por ello, precisamos revisar el concepto de genealogía de Nietzsche, como lo sugiere Foucault ${ }^{10}$ en un juego entre de oposición y equivalencia entre Herkunft (procedencia) y Entstehung (emergencia) frente a Ursprung (origen). Seguido a ello,

\footnotetext{
${ }^{7}$ Podría recordarse al respecto el análisis que elabora François Dosse, quien historiza la amistad filosófica de estos pensadores, junto a las relaciones y disidencias de sus pensamientos. Aunque no coincidimos plenamente con su perspectiva, debido a la importancia otorgada por el historiador a detalles pueriles sobre los autores, que nada aportan a la comprensión de sus pensamientos. DOSSE, François, Gilles Deleuze y Félix Guattari. Biografía cruzada, Buenos Aires, Fondo de Cultura Económica, 2009, pp. 399-429

${ }^{8}$ Op. Cit. DELEUZE, Gilles, GUATTARI, Félix, Mil Mesetas, p. 16

9 Ídem, p. 13

${ }^{10}$ FOUCAULT, Michel, El orden del discurso. Madrid. Ediciones de la Piqueta. 1996, pp. 15-17
} 
Pverea Etinexaxio Revista Digital de OFilosofla ISSN 1850-3578 2013 - Vol. 8 - Número VIII - Resistencia, Chaco, Argentina. Pp. 174 - 196

señalaremos las relaciones que tal concepto tendría con la categoría de rizoma. En resumen, abordaremos esta cuestión desde tres ejes; 1- los métodos arqueológico y genealógico en M. Foucault, 2- el rizoma como método predilecto en G. Deleuze y su relación con la genealogía nietzscheana y foucaultiana a través de las hipótesis expuestas y finalmente, 3- articularemos ambos pensamientos, extraeremos las consecuencias que esto implicaría y revisaremos las hipótesis formuladas.

\section{Métodos y efectos de verdad en M. Foucault.}

"Se objetará que Foucault no hace otra cosa que afinar análisis muy clásicos basados en el contexto. Esto sería desconocer la novedad de los criterios que instaura, precisamente para demostrar que se puede decir una frase o formular una

proposición sin tener siempre el mismo emplazamiento en el enunciado correspondiente, sin reproducir las mismas singularidades". DELEUZE, Gilles.

Foucault, p. 37.

Los análisis de M. Foucault, específicamente los que competen a la mirada metodológica, están transitados por el problema del poder, su relación ineludible con el saber, y los efectos de verdad que se construyen entre ellos. La historia es el objeto de análisis predilecto en el estudio de los enunciados, puesto que sólo es posible analizar aquello que se dice verdadero ${ }^{11}$ Es decir, la verdad para Foucault, siguiendo el legado nietzscheano, es una invención ${ }^{12}$ (Erfindung) en su doble acepción: tanto ruptura, irrupción sorpresiva, como invención de procedencia mezquina, y cuyo efecto de superficie se le ha dado en llamar conocimiento. Efecto que, debido a la necesidad gregaria del hombre, proviene de la lucha y la violencia sobre el objeto. Pero además supone una posición estratégica en la lucha entre los instintos. Asimismo, el concepto de hombre ${ }^{13}$ es otra invención humana, que es posible precisar la fecha de nacimiento, y acaso su desaparición ${ }^{14}$. Más adelante ampliaremos sobre estas cuestiones, pero su revisión tiene otro objetivo, a saber: dilucidar algunas de las características de su construcción teórica y metodológica en lo que se denomina el giro del pensamiento foucaultiano ${ }^{15}$. Nos referimos al paso de la arqueología de los saberes a la genealogía de los poderes. Con la salvedad de no confundir estos momentos como instancias separadas, puesto

\footnotetext{
${ }^{11}$ FOUCAULT, Michel. Nietzsche, la genealogía, la historia. Valencia, Pre-textos. 2004, p. 20

${ }^{12}$ FOUCAULT, Michel. La verdad y las formas jurídicas. Barcelona. Gedisa. 2003, pp. 20-27

${ }^{13}$ Desde una perspectiva genealógica el autor se refiere al individuo y su relación con el poder "Vale decir que el individuo no es quien está enfrente del poder; es, creo, uno de sus efectos primeros." Op. Cit. FOUCAULT, Michael, Defender la sociedad. 2008, p. 38

${ }^{14}$ FOUCAULT, Michel. Las palabras y las cosas. Buenos Aires. Siglo XXI Editores. 2007, p. 9

${ }^{15}$ BEAULIEU, Alain. Cuerpo y acontecimiento. La estética de Gilles Deleuze. Buenos Aires. Letra viva. 2012, p. 33
} 
Q Nueva Etinexaxio Revista Digital de OFilosofia ISSN 1850-3578 2013 - Vol. 8 - Número VIII - Resistencia, Chaco, Argentina. Pp. 174 - 196

que, ambos métodos trabajan en conjunto. Este paulatino desplazamiento de uno a otro momento queda explicitado claramente en algunas de sus obras más significativas. Tal es el caso de Vigilar y Castigar, obra que muestra el paso de la sociedad de soberanía a la sociedad disciplinaria, al tiempo que marca el umbral entre la sociedad disciplinaria y la sociedad de control $^{16}$.

El sentido de las palabras de Deleuze en la obra que le dedica al autor, expresan la coyuntura en la que Foucault planteara el método arqueológico. Como destaca Beaulieu ${ }^{17}$ el análisis de las formaciones discursivas en la perspectiva foucualtiana debate con los intentos de explicar la historia desde el punto de vista dialéctico. En tal sentido, los supuestos análisis contextuales en Foucault no son tales, por el contrario, pretenden mostrar las discontinuidades del saber y de las formaciones discursivas - para decir la misma frase y expresar una singular diferenciadirá Deleuze ${ }^{18}$, frente al predominio tanto de la historia de las ideas como de su forma contemporánea: el proyecto hermenéutico de Gadamer. Su rechazo a tal tentativa proviene de la relación que vislumbra con las Filosofías de la Historia, e incluso con la fenomenología de la que es heredera ${ }^{19}$. Su proyecto pretende analizar las formaciones discursivas sin referirlas al contexto de aparición, mostrando las discontinuidades, sus modos de formación y desaparición en la respectiva distancia temporal, proyecto que posteriormente otorgará mayor importancia a los poderes en pugna. Justamente en relación a la pretensiosa y trascendental idea de una interpretación bajo la que subyacería una verdad ${ }^{20}$, pretensión que en la contemporaneidad toma el nombre de hermenéutica, escribe una obra que pone en

\footnotetext{
${ }^{16}$ Coincidimos con la afirmación de G. Agamben, (Cfr. AGAMBEN, Giorgio. Signatura rerum. Sobre el método. Buenos Aires. Adriana Hidalgo. 2009, p 24) para quien el concepto de panóptico desarrollado por Foucault en esta obra tendría una función estratégica, al ser al mismo tiempo la figura epistemológica que definiría la sociedad disciplinar, y el umbral o la transición hacia la actual "sociedad de control".

${ }^{17}$ Op. Cit. BEAULIEU, Alain. Cuerpo y acontecimiento. La estética de Gilles Deleuze. pp. 31-33

${ }^{18}$ Es notable la estrecha vinculación que establecen los autores, quizás debido a la impronta de Mayo del 68', respecto de la necesidad de afirmar e insertar la diferencia en el ámbito teórico-discursivo, que es asimismo político, frente la preeminencia dicotómica que supone la lógica aristotélica del tercero excluido. (Cfr. DELEUZE, Gilles. Diferencia y repetición. Buenos Aires. Amorrortu. 2006)

${ }^{19}$ A través de su análisis de la diseminación de la Filosofía y de su relación con el afuera, le Blanc parte de la hipótesis de la primacía de la práctica en el pensamiento foucualtiano y deduce que en la propuesta teórica del autor ha querido desvincularse de los datos inmediatos a la conciencia que supone la fenomenología. De allí, afirma el autor: "Los discursos tal sólo adquieren sentido con referencia a los poderes que los atraviesan". (Cfr. LE BLANC, Guillaume. El pensamiento Foucault. Buenos. Aires. Amorrortu. 2008, pp. 27-28)

20 "(La arqueología) no es la vuelta al secreto mismo del origen, es la descripción sistemática de un discurso-objeto". FOUCAULT, Michel. La arqueología del saber. Buenos Aires. Siglo XXI Editores. 2005, p. 235
} 
Pverea Etinexaxio Revista Digital de OFilosofla ISSN 1850-3578 2013 - Vol. 8 - Número VIII - Resistencia, Chaco, Argentina. Pp. 174 - 196

cuestión la continuidad discursiva de la historia: la Arqueología del saber. Así se refiere allí sobre la historia de las ideas:

"La historia de las ideas es la disciplina de los comienzos y de los fines, la descripción de las continuidades oscuras y de los retornos, la reconstitución de los desarrollos en la forma lineal de la historia. Pero también, y con ello, puede incluso describir, de un dominio al otro, todo el juego de los cambios y de los intermediarios;..." Ídem, p. 231

Comprender la historia en términos continuistas, lineales y progresivos, tanto en el ámbito individual como colectivo, ha sido el proyecto pensado y concretado por la corriente historicista. De allí que Foucault advierta que el tratamiento discursivo sobre historia que realiza la Historia de las Ideas, en tanto exponente de tal pensamiento, alberga una serie de presupuestos que son valores que ponen en juego en los campos discursivos. Sin embargo, la arqueología analiza los acontecimientos discursivos que conforman lo regular, pero teniendo en cuenta los diferentes tipos y niveles, en entrecruzamiento con otras continuidades lingüísticas y lógicas ${ }^{21}$. Asimismo, la arqueología puede también analizar las jerarquías de las regularidades enunciativas. De este modo caracteriza la función:

"Se puede describir así un árbol de derivación enunciativa: en su base, los enunciados que utilizan la regla de formación en su extensión más amplia; en la cima, y después de un cierto número de ramificaciones, los enunciados que emplean la misma regularidad, pero más finamente articulada, mas delimitada y localizada en su extensión." Ídem, p. 247

Pese a la descripción de las regularidades y las derivaciones, Foucault no se cansa de delimitar el campo y el modo de análisis discursivo de su método. Puesto que no busca un principio general de la regularidad, sea este cronológico, identitario o totalizador. Por el contrario, quiere mostrar la autonomía del discurso que tiene un tipo propio de historicidad, pero que se relaciona con un conjunto de otros discursos de manera diversa. En efecto, pretende indagar en cada práctica discursiva las reglas que las constituyen, sean de acumulación, de exclusión, derivación o de reactivación. Sin embargo, esto lo realiza en aras de analizar las discontinuidades discursivas, en múltiples saberes, frente a un desarrollo de la historia que no ha cesado de hacer de su elemento ineludible el documento, el objeto de análisis predilecto para reconstruir el pasado en la forma de memoria. Vale decir que esta comprensión de la historia en su función memorizadora encuentra su punto de conexión con la historia

\footnotetext{
${ }^{21}$ Ídem, p. 246
} 
PNeve Etinexania Revista Digital de OFilosofia ISSN 1850-3578 2013 - Vol. 8 - Número VIII - Resistencia, Chaco, Argentina. Pp. 174 - 196

anticuaria de la que hablara Nietzsche $e^{22}$, por ello adquiere su justificación antropológica ${ }^{23}$. El sentido de la historia para la vida se une con la justificación del sentido de la existencia humana, puesto que nuestra otrora efímera y singular existencia encuentra su lugar teleológico en la comunidad y en la tradición que nos cobija. Esta perspectiva de la historia, tan agradable y con enorme incidencia en la vida social, fue puesta en cuestión por la autor dada la limitación que el sentido retrospectivo implica. En tal consideración, la vida actual, lo nuevo, lo que está en vías de realizarse es denostado por esta mirada que solo conserva la vida, pero no puede crear nuevos modos de vida. Alrededor de esta cuestión, Foucault propone la arqueología como disciplina de los monumentos y se embarca en la realización de su descripción. Ciertamente, tal proyecto implica la comprensión de los discursos desde su efecto de superficie ${ }^{24}$ en la constitución de las series y sus relaciones, donde se inscribirían los análisis de acontecimientos regulares, tal como lo señala le Blanc ${ }^{25}$. Sin embargo, este procedimiento presenta una función paradójica, ya que al mismo tiempo que es el instrumento del historiador, es su objeto de investigación ${ }^{26}$. Ahora bien, de modo similar como funcionaba el sentido de lo ordinario en los acontecimientos, la discontinuidad va a torcer su sentido para erigirse el elemento positivo que determina y valida su análisis. Discontinuidad que disolverá la posibilidad de una historia global de época, cuyo sistema de relaciones homogéneas, mantienen entre sí principios de coherencia y cohesión. Sin embargo, esta propuesta plantea un conjunto singular de problemas que Foucault dará batalla frente a las acusaciones que lo tildan de estructuralista. Para ello, hace patente que su propuesta se aleja de la comprensión tradicional de la historia, cuya característica continua implica la función fundadora del sujeto y la preeminencia del sistema ante el devenir de los acontecimientos.

En resumen, podemos afirmar que el análisis de las formaciones discursivas en una primera tentativa arqueológica, tiene en muchos aspectos características similares a los análisis de G.

\footnotetext{
${ }^{22}$ NIETZSCHE, Friedrich. Sobre la utilidad y los perjuicios de la historia para la vida. Madrid. EDAF. 2000, pp. 59-67

${ }_{23}$ Op. Cit. FOUCAULT, Michel, La arqueología del saber, 2005, p. 10.

24 Ídem, p. 11

25 Coincidimos con el autor, para quien en el análisis de las vidas ordinarias residiría una de los lugares de encuentro de Foucault con el pensamiento de G. Deleuze, para quien la categoría de lo ordinario ha sido devaluada a través del "buen sentido" y del "sentido común" que rebajan las diferencias a la categoría de lo Mismo. En similar perspectiva, Foucault va a desarrollar el estudio crítico de lo ordinario en la Arqueología del saber. le Blanc (Cfr. Op. Cit. LE BLANC, Guillaume, El pensamiento Foucault. 2008, pp. 61 y 67). Puede encontrarse este análisis acerca del predominio de lo mismo frente a la urgencia de pensar lo Otro en: Op. Cit. FOUCAULT, Michael. La arqueología del saber. 2005, p. 20

${ }^{26}$ Ídem, p. 14.
} 
Pverea Etinexaxio Revista Digital de OFilosofla ISSN 1850-3578 2013 - Vol. 8 - Número VIII - Resistencia, Chaco, Argentina. Pp. 174 - 196

Deleuze en esa obra que constituyó un paso más allá de los estudios críticos y revisionistas de la Historia de la Filosofía, a saber: Lógica del sentido. Como recientemente explicitábamos a propósito del lugar de lo ordinario, la lógica del sentido es paradójica al introducir el sinsentido en el juego del pensamiento.

Podemos sospechar que Foucault no creyó en el simple estudio de discontinuo de las "continuidades", sino que supo que acaso esta sea una manera -provisoria, quizás- para entender el sistema de poder que las rigen ${ }^{27}$. Años más tarde de la publicación de la Arqueología, en el contexto de las conferencias pronunciadas en Río de Janeiro en 1973, explica el concepto de esta manera:

"La función del análisis arqueológico sería, en primer lugar, descubrir estas continuidades oscuras que hemos incorporado y, en segundo lugar, partiendo del estudio de su formación, comprobar la utilidad que han tenido y que aún hoy siguen teniendo; es decir, como actúan en la actual economía de nuestras condiciones de existencia. En tercer lugar, el análisis histórico-arqueológico permitiría además determinar a qué sistema de poder están ligadas estas bases o continuidades, y por consiguiente, como abordarlas" ${ }^{28}$

Vislumbramos en la explicación del análisis arqueológico en esta obra una nueva relación del estudio de las formaciones discursivas en la historia con los efectos de poder que suscitan y, en general, con la conformación de la verdad, habida cuenta de su incidencia en "nuestras condiciones de existencia". Sin embargo, fue alrededor de 1975, con la redacción y posterior publicación de Vigilar y Castigar cuando Foucault transita el paso del análisis arqueológico de los saberes y de las formaciones discursivas, a través del trabajo sobre el archivo, hacia una genealogía de los poderes. Poderes que en la sociedad de soberanía expresaban su carácter punitivo en forma de espectáculo.

Foucault analiza cómo la "fiesta punitiva" comienza a extinguirse en el periodo que va desde fines del s. XVIII hacia comienzos del siglo XIX. Paulatinamente el proceso punitivo desaparece en su forma de espectáculo y comienza a ser un proceso oculto y administrativo ${ }^{29}$. Mientras que anteriormente el castigo debía estar inscripto en el cuerpo a través de las marcas, ahora se vuelve púdico, el castigo pasa por la suspensión del derecho, mediante el uso de su

${ }^{27}$ Consideramos que su propio procedimiento de escritura implicaría un desplazamiento de las delimitaciones que marcan el sentido: "Más de uno, como yo sin duda, escribe para perder el rostro. No me pregunten quien soy, ni me pidan que permanencia invariable: es una moral de estado civil la que rige nuestra documentación. Que nos deje en paz cuando se trata de escribir". Óp. Cit, FOUCAULT, Michel. La arqueología del saber, p. 29

${ }^{28}$ Op. Cit. FOUCAULT, Michael. La verdad y las formas jurídicas, p. 181

${ }^{29}$ Cfr. FOUCAULT, Michel. Vigilar y Castigar. Buenos Aires. Siglo XXI Editores. 2002, pp. 11-37 
Pverea Etinexaxio Revista Digital de OFilosofla ISSN 1850-3578 2013 - Vol. 8 - Número VIII - Resistencia, Chaco, Argentina. Pp. 174 - 196

libertad. A esto llama el autor, la "utopía del pudor judicial" ${ }^{30}$. Sin embargo, el cuerpo no es ya expuesto al castigo a través del suplicio y su resonancia, sino que encuentra formas más sutiles. Es decir, a través del trabajo de archivo, Foucault da cuenta del desplazamiento de los objetos de análisis, los nuevos procedimientos para abordarlos y los nuevos regímenes de verdad. En este sentido, el análisis de las formaciones discursivas en el nuevo sistema penal se va a articular con la genealogía de los poderes que instituyen una sociedad disciplinaria. En la genealogía entran en escena nuevos personajes -los expertos- quienes juzgan la "peligrosidad" de los condenados en la esfera social. Es decir, esto se articula con el poder de castigar -que antaño fuera de los jueces- y con los discursos científicos en ascenso, cuyo saber, técnicas y procedimientos va a conformar el objeto del libro, además de ser un estudio de la subjetividad moderna. Así lo expresa el autor:

"Objetivo de este libro: una historia correlativa del alma moderna y de un nuevo poder de juzgar; una genealogía del actual complejo científico-judicial en el que el poder de castigar toma su apoyo, recibe sus justificaciones y sus reglas, extiende sus efectos y disimula su exorbitante singularidad" ${ }^{\prime 31}$.

A través de tal objetivo el autor va a estudiar los sistemas punitivos desde una "economía política del cuerpo", inscripta en un campo político (sociedad capitalista en ascenso) y que funciona con los procedimientos de los saberes, quienes en su acción estratégica, conforman las tecnologías políticas de los cuerpos. El nuevo objeto de análisis genealógico son estos micropoderes, que funcionan en el orden del saber estratégico y se inscriben en los cuerpos conformando una "anatomía política" ${ }^{32}$. Análisis de los cuerpos o máquinas ${ }^{33}$, que en la sociedad disciplinar se convertirá en un estudio del detalle, para la conformación de sujetos dóciles-útiles ${ }^{34}$ a las necesidades de la sociedad que al mismo tiempo que los produce, los

\footnotetext{
${ }^{30}$ Cfr. Ídem, p. 19

31 Ídem, p. 29

32 Ídem, p. 35

${ }^{33}$ Cfr. FOUCAULT, Michel. Historia de la sexualidad I. La voluntad de saber. Buenos Aires. Siglo XXI Editores. 2011, p. 131

${ }^{34}$ Esta construcción teórica fue analizada por Deleuze en Anti Edipo, obra publicada algunos años antes a Vigilar y Castigar, pero que retomó las investigaciones foucualtianas en torno a la locura. Además en Anti Edipo, G. Deleuze genealogizó los poderes en la sociedad capitalista (Cfr. DELEUZE, Gilles. GUATTARI, Félix. Anti. Edipo. Capitalismo y esquizofrenia. Buenos Aires. Paidós. 2007, p. 54). Podemos suponer que la articulación entre ambos autores dependió de la estrecha vinculación que sus perspectivas tienen con el pensamiento nietzscheano. Así, Nietzsche se pronunciaba sobre la moral: "Toda moral es contraria al laisser aller (dejar ir), es una tiranía que se ejerce contra la <naturaleza> y también contra la <razón>; pero esto no es una objeción contra ella, a menos que se quiera decretar en nombre de otra moral la prohibición de toda tiranía y de toda sinrazón. Lo esencial de toda moral, lo que
} 
Q Nueva Etinexaxio Revista Digital de OFilosofia ISSN 1850-3578 2013 - Vol. 8 - Número VIII - Resistencia, Chaco, Argentina. Pp. 174 - 196

selecciona y los excluye. Cuerpos transidos por los aparatos de poder y de saber, a través de los ejes espaciales y temporales quienes, desde los mecanismos de encierro (familia, escuela, prisión, etc...) construyen sujetos para la inserción social. Este supuesto método de inclusión social, tiene doble faz, que constituye la figura del delincuente ${ }^{35}$. Entendemos que el delincuente como figura o forma de expresión es uno de los aportes más importantes del universo foucaultiano al pensamiento de Deleuze, quien a través suyo ejemplificará y desarrollará su análisis del lenguaje y el poder ${ }^{36}$. Vale asimismo recordar que el estudio sobre el concepto de genealogía en Nietzsche que realiza Foucault se inserta en las problemáticas recientemente abordadas que inscriben a los cuerpos en el orden del saber y del poder. Por ello, recordamos la distinción que realiza el autor para comprender la crítica nietzscheana de la historia a través de la elaboración del concepto de genealogía en diferentes épocas de su producción intelectual.

Foucault ${ }^{37}$ nos recuerda que la genealogía es un saber de las minucias, de los detalles, que trabaja con cautela y que, en general se opone a toda búsqueda del origen. En ocasiones, especialmente en los textos de la Genealogía de la moral ha utilizado para orientar su búsqueda del Ursprung, el término utilizado es Herkunft. Posteriormente, en Humano, demasiado humano, advertirá que su anterior búsqueda era sobre el Ursprung de la moralidad. De allí que los términos, que luego serán utilizados en forma equivalente dan lugar, no sólo a la distinción entre ellos, sino también a la comprensión sobre el alcance de la búsqueda del origen. La distinción realizada por el autor circunscribe el modo de utilización de la genealogía, que podremos poner en tensión respecto al rizoma.

En principio, el sentido de la genealogía como Herkunft, implica la "procedencia", esto es: pertenencia a un grupo, raza o el tipo social. La búsqueda genealógica consiste en encontrar las marcas singulares que han aportado a la conformación de los acontecimientos, lo cual implica que aquello que conocemos es producto de la exterioridad del accidente. Herencia que se inscribe en los cuerpos, como superficie de inscripción de los acontecimientos. Esta herencia, nos dirá Foucault: "no es una adquisición, un saber que se acumule y se solidifique; más bien es un conjunto de fallas, de fisuras..." ${ }^{38}$ Este conjunto de fisuras, fallas o faltas,

constituye su valor inapreciable, es que es una coacción prolongada". (Cfr. NIETZSCHE, Friedrich. Más allá del bien y del mal, Madrid. EDAF. 2006, p. 160)

${ }^{35}$ Op. Cit, FOUCAULT, Michel. Vigilar y Castigar, p. 255

${ }^{36}$ Óp. Cit, DELEUZE, Gilles; GUATTARI, Félix. Mil Mesetas, pp. 71-78

${ }^{37} \mathrm{Cfr}$. Op. Cit. FOUCAULT, Michel. Nietzsche, la genealogía, la historia.

${ }^{38}$ Idem. p. 28 
Q Nueva Etinexaxio Revista Digital de OFilosofia ISSN 1850-3578 2013 - Vol. 8 - Número VIII - Resistencia, Chaco, Argentina. Pp. 174 - 196

atravesará y trasformará los cuerpos a través de la historia, y en tal sentido la genealogía se ubica en esa hendidura.

Por otro lado, el sentido de la genealogía como Entstehung es: emergencia, surgimiento o aparición que se produce a través del juego en una cierta relación de fuerzas. Es además el lugar, el intersticio o el no-lugar ${ }^{39}$ de enfrentamiento de estas fuerzas en la que luchan. Así han sido formados los supuestos teóricos que rigen la vida de los hombres, y que son retomados por la historia. En efecto, Foucault genealogiza la historia al señalar que las luchas en pugna han derivado en formas de dominación, primero inscriptas en los cuerpos (sociedad de soberanía), pero que posteriormente han tomado la forma eufemística de reglas o normas que rigen la vida humana (sociedad disciplinaria). De allí la importancia de los saberes y sus efectos de poder y verdad. Son ellos quienes, como efecto de ciertas prácticas sociales, producen nuevos dominios de saber y objetos/sujetos de este saber. Posteriormente, analiza un nuevo objeto de poder ${ }^{40}$ : la vida en términos de especie, que al mismo tiempo que es la vida (individual) en sí misma o en su pura desnudez ${ }^{41}$, es la vida (colectiva), como población. La función de la regla o norma marca la instancia vacía, y violenta que rige el mecanismo de la historia, quien se apodera de ellas ${ }^{42}$, pero también quien la reproduce. La relación de la genealogía con la historia toma connotaciones muy específicas, cuando se la relaciona con el contexto del biopoder.

Sabemos que la perspectiva foucaultiana a cerca de la historia está atravesada por una cierta interpretación que hace del pensamiento de Nietzsche. La crítica que el francés que elabora sobre la historia supone la distinción entre el sentido "supra histórico" del que hablara

\footnotetext{
${ }^{39}$ Foucault se pronuncia sobre el lugar y el no lugar, en diversas ocasiones. Cabe recordar una de las que consideramos más interesantes: "El cuerpo utópico", y posteriormente: "Las heterotopías", esas dos conferencias que pronunciara alrededor de 1966. Allí trabaja tempranamente la relación entre el cuerpo y el espacio, desplazando su análisis, que pasa de ser una distinción entre lo corporal y lo utópico a convertir lo utópico (o lo Otro) en lo más propio del cuerpo. El juego entre el lugar y el no lugar, lo percibimos cercano a la perspectiva metodológica y ontológica del rizoma deleuziano. (Cfr. FOUCAULT, Michel. El cuerpo utópico. Las Heterotopías. Buenos Aires. Nueva Visión. 2010)

${ }^{40}$ En el último capítulo de la Historia de la sexualidad, Foucault comienza a genealogizar las relaciones de poder (monárquico- disciplinar) que en Vigilar y castigar había revisado, pero ahora lo hace desde el eje transversal del dispositivo sexualidad, que producirá en adelante la vinculación del poder con su nuevo objeto: la vida, conformando el biopoder. (Cfr. FOUCAULT, Michel. Historia de la sexualidad I. La voluntad de saber. Buenos Aires. Siglo XXI Editores. 2011, pp. 127-152)

${ }^{41}$ A partir de tal consideración, G. Agamben va a construir la noción de nuda vida propia del homo sacer y desarrollará la perspectiva foucaultiana derivando en el estudio de los campos de concentración. Cfr. AGAMBEN, Giorgio, Homo sacer I. El poder soberano y la nuda vida. Valencia. Pre-textos. 2010.

${ }^{42}$ Deleuze coincide con esta idea pero advierte la posibilidad de subvertir el juego estratégico de la historia y hacerla devenir, aunque es una posibilidad y siempre se pueden "cristalizar micro fascismos". (Cfr. Op. Cit. DELEUZE, Gilles; GUATTARI, Félix. Mil Mesetas, p. 15)
} 
Q Nueva Etinexaxio Revista Digital de OFilosofla ISSN 1850-3578 2013 - Vol. 8 - Número VIII - Resistencia, Chaco, Argentina. Pp. 174 - 196

Nietzsche ${ }^{43}$ y el "sentido histórico", instrumento privilegiado de la genealogía. Mientras que el primero reduce la diversidad de los acontecimientos a la línea del tiempo, progresivo y teleológico, para la comprensión de un Sujeto que a partir de tal proceso será en adelante histórico, el segundo introduce el azar, el devenir y la disociación o lo discontinuo en los cuerpos que expresan la "historia efectiva" ${ }^{44}$. Ella se caracteriza por hacer un movimiento inverso al de los historiadores, para comprender en los cuerpos los movimientos de intensidades y energías diferenciales, sin dejar de permitirse ser un saber perspectivo. La conformación de este concepto de historia, producto de la lucha y de las relaciones de fuerza que están en pugna, depende de una cierta comprensión del concepto de Voluntad de Poder. Si bien no podemos detenernos en emprender un análisis del alcance y la pertinencia de la interpretación foucaultiana de tal concepto, creemos que su lectura realiza un uso del concepto para expresar su propia comprensión de la historia, por ello puede realizar la dilucidación del "sentido histórico" de Nietzsche y la genealogía del concepto de historia. Realiza similar apropiación con el concepto de genealogía, articulándolo con la Voluntad de Poder $^{45}$. Advertimos este uso del concepto en otras obras del autor, como es el caso de $E I$ orden del Discurso. Allí, encontramos un antecedente de los tres usos del sentido histórico ${ }^{46}$ que se oponen al modelo de la memoria. Dado que, con el afán de explicitar su hipótesis de los procedimientos que trabajan en el interior de las producciones discursivas de toda sociedad, da las pautas para comprender la voluntad de saber que es al mismo tiempo, voluntad de verdad. En el análisis de la formación de los acontecimientos discursivos introduce las nociones de azar, discontinuidad y materialidad para indicar las posibilidades de conjurar la historia de los historiadores, es decir, la historia de las ideas ${ }^{47}$.

Sin embargo, es ya en el análisis del nuevo modo de conformación del poder, es decir, entrando en el ámbito del biopoder, cuando Foucault explicita otra manera de comprender la genealogía y su relación con la historia. Nos situamos no ya en la captura de la vida para su

\footnotetext{
${ }^{43}$ Op. Cit. FOUCAULT, Michel. Nietzsche, la genealogía, la historia, p. 43

${ }^{44}$ Idem. pp. 46

${ }^{45}$ Creemos que nuestra posición sobre la articulación entre Voluntad de Poder y genealogía y el uso de la última como recurso metodológico encontraría su demostración en la siguiente cita: "Pero si es esa la genealogía de la historia, ¿cómo puede convertirse ella misma en análisis genealógico? (...) Pues únicamente porque uno se apodera de ella, porque la domina y la vuelve contra su nacimiento. Tal es, en efecto lo propio de la Entstehung..." Idem, p. 61

46 Nos referimos al uso paródico y destructor de la realidad contra la historia reminiscencia, al disociativo y destructor de la identidad, frente a la historia-continuidad, y al uso sacrificatorio y destructor de la verdad, contra la historia-conocimiento, que constituyen finalmente el paso de la destrucción del sujeto de conocimiento a la voluntad de saber. (Cfr. Idem, pp. 63-75)

${ }^{47}$ Cfr. Ídem. Pp. 56-59
} 
Pverea Etinexaxio Revista Digital de OFilosofla ISSN 1850-3578 2013 - Vol. 8 - Número VIII - Resistencia, Chaco, Argentina. Pp. 174 - 196

supresión o "el derecho de hacer morir o de dejar vivir" la muerte" ${ }^{\prime 49}$. Queremos decir, tal como lo expusiera Foucault, el biopoder fue el elemento indispensable del capitalismo, quien necesitó de métodos, instituciones y técnicas para su ejercicio y su incidencia en los cuerpos. Constituye un nuevo campo de análisis político, en el que entra la vida y sus mecanismos en el dominio de las técnicas de trasformación de la vida humana, en términos individuales y colectivos (especie ${ }^{50}$ ). Es decir, pasamos del poder monárquico hacia un poder disciplinario y conjuntamente normalizador. El análisis señala un nuevo modo de pensar el poder en el contexto del capitalismo, pero también indica la artificialidad y utilidad meramente metodológica de las supuestas etapas en el pensamiento focaultiano, ya que no abandona el análisis del poder disciplinario ni olvida su permanencia y los efectos de verdad que produce. Su análisis de la norma da las pautas para comprender esta conjunción, ya que necesita de un continuum de aparatos para la regulación de la vida ${ }^{51}$, de allí también la importancia del sexo o de la sexualidad en el juego político.

Este nuevo modo de conformación del poder, también lo hace patente en el curso dictado entre Enero y Marzo de 1976 en el Collège de France publicado como Defender la sociedad. El análisis realizado en esta ocasión comienza con la recapitulación y la reflexión sobre los cursos de los últimos años. Este ejercicio da lugar a una serie de conclusiones parciales que le servirán de disparadores de nuevas investigaciones: el saber histórico de las luchas, que provienen de la crítica de los saberes sometidos ${ }^{52}$. A partir de ello, define en principio su análisis como genealógico:

"Llamemos, si ustedes quieren, genealogía al acoplamiento de los conocimientos eruditos y las memorias locales, acoplamiento que permite la constitución de un saber histórico de las luchas y la utilización de ese saber en las tácticas actuales. Ésa sería, pues, la definición provisoria de las genealogías que traté de hacer con ustedes durante los últimos años" ${ }^{53}$

En esta definición se trataría de hacer manifiesta la necesidad de posicionar a la genealogía como una metodología que se opone al saber científico positivista, y por ello anticientífica,

\footnotetext{
${ }^{48}$ Op. Cit. FOUCAULT, Michel. Historia de la sexualidad I. La voluntad de saber, p. 128.

49 Ídem. 130

50 Ídem, p. 135

51 Ídem, p. 136

52 Op. Cit, FOUCAULT, Michel. Defender la sociedad, pp. 20-22

53 Ídem, pp. 21-22
} 
Pverea Etinexaxio Revista Digital de OFilosofla ISSN 1850-3578 2013 - Vol. 8 - Número VIII - Resistencia, Chaco, Argentina. Pp. 174 - 196

pero en pos de contrarrestar los efectos de poder/verdad del discurso científico. Especifica su análisis y articula nuevamente cierta relación con el pensamiento de G. Deleuze:

"La genealogía sería, entonces, con respecto al proyecto de una inscripción de los saberes en la jerarquía de poder propia de la ciencia, una especie de empresa para romper el sometimiento de los saberes históricos y liberarlos, es decir, hacerlos capaces de oposición y lucha contra la coerción de un discurso teórico unitario, formal y científico. La reactivación de los saberes locales -menores, diría acaso Deleuze- ${ }^{1}$ contra la jerarquización científica del conocimiento y sus efectos de poder intrínsecos es el proyecto de esas genealogías en desorden y hechas añicos. En dos palabras, yo diría lo siguiente: la arqueología sería el método propio del análisis de las discursividades locales, y la genealogía, la táctica que, a partir de esas discursividades locales así descriptas, pone en juego los saberes liberados del sometimiento que se desprenden de ellas. Esto, para restituir el proyecto de conjunto." ${ }^{54}$

De esta manera, su análisis se focalizará sobre el poder y su ejercicio en un saber como la economía, que atraviesa el pensamiento liberal y marxista del poder, pero que implica una cierta relación estratégica de fuerzas. Es decir, un análisis del poder que no tiene en cuenta tanto la represión sino el ejercicio del poder a través de las tácticas, estrategias y relaciones de fuerza. Por ello, puede pensar la política como la continuación de la guerra por otros medios ${ }^{55}$. En consecuencia, la genealogía como táctica está inserta en la lucha de fuerzas por la liberación de los saberes, que transita el paso de las técnicas disciplinarias al biopoder (los racismos de Estado ${ }^{56}$ ), y en tal sentido, advertimos una tendencia más productiva e inventiva de ella como método filosófico. No es casual que cite el concepto de minoría de Deleuze. Lo minoritario, en este caso referido a los saberes, es una cuestión de devenir y no tiene relación con características cuantitativas. Por el contrario, se trata de un desprendimiento o liberación de lo que había sido capturado por el poder Mayoritario, o los modos de dominación estratificados. Así entendido, la genealogía como método filosófico podría ser una estrategia de análisis discursivo que implique la posibilidad de fuga o liberación de los saberes/poderes, y asimismo, ella podría implicar nuevas alternativas en las producciones de saber y sus efectos de verdad.

\section{El rizoma: anti genealogía y anti método.}

\footnotetext{
${ }^{54}$ Ídem, pp. 23-24

55 Ídem, pp. 28

${ }^{56}$ Ídem, p. 233
} 
eNweva Ettineraxia Revista Digital de OFilosofia ISSN 1850-3578 2013 - Vol. 8 - Número VIII - Resistencia, Chaco, Argentina. Pp. 174 - 196

Igualmente, Deleuze revisa una serie de métodos a lo largo de su producción intelectual, dependiendo en cada época de las problemáticas que lo invitan a pensar. Así, según el análisis realizado por J. Rajchman ${ }^{57}$ sobre los períodos de invención en el autor, podemos encontrar una serie de métodos. Sin detenernos en cada una de las épocas de producción intelectual, advertimos que desarrolla por lo menos tres métodos, que convergen en la necesidad de comprender qué significa pensar y en abordar los modos como ha sido construida una cierta imagen del pensamiento ${ }^{58}$. Nos referimos al método trascendental en $\mathrm{Kant}^{59}$, la dramatización en Nietzsche ${ }^{60}$, y la intuición en Bergson ${ }^{61}$. Sin embargo, y pese al influjo de tales métodos en la producción deleuziana, nos interesa abordar el método por excelencia que expondrá en Mil Mesetas: el rizoma, cuya especificidad la desarrolla el autor en la introducción, pero que subsiste en diferentes partes de su obra.

Habíamos dejado en suspenso la perspectiva metodológica de G. Deleuze. Ciertamente, al comienzo de este escrito poníamos de manifiesto la característica anti genealógica que $\mathrm{G}$. Deleuze y F. Guattari esbozan sobre el rizoma ${ }^{62}$. Ahora bien, si recordamos la importancia que en el pensamiento de Foucault tiene este concepto, pareciera que sus perspectivas se escinden en lo que respecta a lo metodológico, e incluso en los intereses y horizontes conceptuales de ambos autores, dado que el cómo da cuenta del sentido de lo dicho, o en términos de Deleuze: "No hay ninguna diferencia entre aquello de lo que un libro habla y cómo está hecho" ${ }^{\prime 63}$. Por ello, necesitamos abocarnos a la tarea de comprender el sentido del concepto de rizoma y su relación con la genealogía. Sobre todo cuando el método genealógico es utilizado por Deleuze, en el sentido de crítica al valor de los valores, es decir, a los valores en curso ${ }^{64}$. ¿En qué oportunidades podemos afirmar que G. Deleuze realiza este procedimiento? Basta recordar, por ejemplo, la construcción del concepto de imagen de pensamiento $^{65}$, que implica un análisis genealógico de la conformación de lo que significa pensar y la sedimentación de su sentido en la Historia de la Filosofía, para pensar la diferencia en sí, en detrimento de las lógicas dicotómicas comunes al pensar filosófico occidental. Años más tarde, en 1972, a partir de la necesidad de comprender la “perversión del deseo

\footnotetext{
${ }^{57}$ RAJCHMAN, John. Deleuze. Un mapa. Buenos Aires. Nueva visión. 2004, pp. 31-32

${ }^{58}$ DELEUZE, Gilles. Diferencia y repetición. Buenos Aires. Amorrortu. 2006, pp. 201 y ss.

${ }^{59}$ Cfr. DELEUZE, Gilles. La filosofía critica de Kant. Madrid. Ediciones Cátedra. 2011, pp. 11-26

${ }^{60}$ Cfr. DELEUZE, Gilles. La isla desierta y otros escritos. Valencia. Pre-textos, pp. 127-153

${ }^{61}$ Cfr. Ídem. pp. 31-43

${ }^{62}$ Óp. Cit. DELEUZE, Gilles; GUATTARI, Félix. Mil Mesetas. pp. 13 y 16

63 Ídem, p. 10.

${ }^{64}$ NIETZSCHE, Friedrich. La genealogía de la moral. Madrid. EDAF. 2000, p. 47

${ }^{65}$ Cfr. DELEUZE, Gilles. Diferencia y repetición. Buenos Aires. Amorrortu. 2006.
} 
Q Nueva Etinexaxio Revista Digital de OFilosofla ISSN 1850-3578 2013 - Vol. 8 - Número VIII - Resistencia, Chaco, Argentina. Pp. 174 - 196

gregario" ${ }^{\prime 66}$ o porqué lo hombres desearon el fascismo, se embarca junto a F. Guattari en la tarea de desarticular los mecanismos de poder represivos en la sociedad capitalista, y emprenden un análisis que podríamos denominar de genealógico sobre la conformación del Estado $^{67}$. Estas dos obras, muestran en principio que el método es caro a su perspectiva y además que él aún más que Foucault lo utiliza sin indagarlo previamente.

Nuestra hipótesis ante este problema consiste en advertir en esta "etapa de su producción intelectual" -con el artificio que esto supone- constituye una nueva posición filosófica, y con ello queremos decir, principalmente política y estética, pero además ética. Consideramos que desde Mil Mesetas, y por lo tanto desde su introducción, su análisis a través del rizoma, va a ser similar al procedimiento genealógico analizado por M. Foucault, pero va a tender a un sentido más cercano a Entstehung (invención o emergencia) que a Herkunft, (procedencia o pertenencia). Comprendido de este modo, derivaría en tres efectos. En primer lugar, sería un procedimiento fuertemente pragmático, más inventivo que crítico y en consecuencia, más cercano a las perspectivas estéticas. En segundo lugar, implicaría una ontología de encuentros o agenciamientos de multiplicidades, que derivaría en una composición ético-política deudora de Spinoza, y que se expresaría en una suerte de "proyecto" en el Cuerpo sin Órganos. Finalmente, implicaría un modo de pensar el método ajeno a la mirada tradicional que lo considera en términos de modelo, camino o procedimiento y sería en tal sentido un anti método, que apela a la producción y a la experimentación.

Sin embargo, para desarrollar esta hipótesis y sus derivas consideramos pertinente a la investigación recapitular las características del rizoma, acaso para articular estas expresiones en su contexto discursivo. El rizoma es el título dado a la introducción de Mil Mesetas, donde en su prefacio, los autores ponen de manifiesto que es un libro que debido a su forma puede ser leído de manera aleatoria, salvo la conclusión. En tal sentido, la obra comienza con el rizoma, que versa sobre el libro y la escritura ${ }^{68}$. Así, el libro, entendido como multiplicidad o agenciamiento maquínico ${ }^{69}$ está en relación con otros agenciamientos (con el afuera) y en ese sentido, tanto con estratos como con Cuerpos sin Órganos que funcionan en un mismo plano de consistencia o de inmanencia ${ }^{70}$. En consecuencia, el libro en tanto pequeña máquina,

\footnotetext{
${ }^{66}$ Óp. Cit, DELEUZE, Gilles; GUATTARI, Félix. Anti. Edipo, p. 36

${ }^{67}$ Ídem., pp. 190-247

${ }^{68}$ Óp. Cit, DELEUZE, Gilles; GUATTARI, Félix. Mil Mesetas, p. 9

${ }^{69}$ ídem., p. 10

${ }^{70}$ Idem.
} 
Q Nueva Etinexaxio Revista Digital de OFilosofla ISSN 1850-3578 2013 - Vol. 8 - Número VIII - Resistencia, Chaco, Argentina. Pp. 174 - 196

expresa la convergencia de multiplicidades y la escritura es el trazado de un plano, una cartografía de esas multiplicidades.

Posteriormente, van a desarrollar su análisis del libro, de la escritura, y según advertimos, la crítica de las lógicas imperantes que conforman las imágenes de pensamiento, desde tres categorías: el libro-raíz, el sistema raicilla o raíz fasciculada y el rizoma. Hasta aquí, revisa algunas de las lógicas más comunes en el discurso filosófico que ya habían sido analizadas genealógicamente y en detalle en Diferencia y repetición. Sin embargo, entendemos que en la elaboración de un nuevo método de análisis discursivo, que también implica lo político ${ }^{71}$, se aleja de la convencional manera de pensarlo y nos invita a la acción. Dado que "lo múltiple hay que hacerlo"72, invoca a la construcción/invención del propio método y no al simple uso del mismo. Incluso sus seis principios (conexión y heterogeneidad, multiplicidad, ruptura asignificante, cartografía y calcomanía) invitan a experimentar las conexiones múltiples de agenciamientos colectivos de enunciación con cualquier eslabón semiótico, sin conformar unidades y con posibilidad de huir en líneas de desterritorialización ${ }^{73}$. En este sentido, se explica que el rizoma sea una anti genealogía, ya que tal como lo señala J. L. Pardo ${ }^{74}$, el análisis filosófico y la misma filosofía es para Deleuze temporal pero no histórica. Queremos decir con ello que, no puede insertarse en el modo de proceder característico que la historia ha tenido, una mirada hacia el pasado que es reductora de las diferencias y reproductora de lo mismo. El sentido de antigenalogia, pensando en el "árbol genealógico", implica una mirada no retrospectiva sino abocada a construir nuevos horizontes. Posiblemente, si lo revisamos en detalle, ello no sea un elemento discordante con Foucault, por lo menos desde la perspectiva deleuziana. Deleuze considera que en la última etapa ${ }^{75}$ del pensamiento de Foucault, su amigo está pensando en las reglas que implican ser afectados por los otros, donde los "otros" también son las propias fuerzas que se pliegan para inventar nuevos modos de existencia, modos que afirmen la vida. Así se expresaba:

“Franquear la línea de fuerza, rebasar el poder, ello significaría plegar la fuerza, conseguir que se afecte a sí misma en lugar de afectar a otras fuerzas: un "pliegue", según Foucault, una relación de la fuerza consigo misma. Hay que "doblar" la relación de fuerzas mediante una relación consigo mismo que nos

\footnotetext{
${ }^{71}$ Óp. Cit. DELEUZE, Gilles; GUATTARI, Félix. Mil Mesetas, p. 13

72 Ídem, p. 12

${ }^{73}$ Ídem, p. 18

74 PARDO, José Luis. El cuerpo sin órganos. Presentación de Gilles Deleuze. Valencia. Pre-textos. 2011, p. 103

${ }^{75}$ Nos referimos a los cursos realizados en el Còllege de France durante la década del 80`.
} 
QNueva Etinexaxio Revista Digital de OFilosofia ISSN 1850-3578 2013 - Vol. 8 - Número VIII - Resistencia, Chaco, Argentina. Pp. 174 - 196

permite resistir, escapar, reorientar la vida o la muerte contra el poder. Esto es, según Foucault, lo que inventaron los griegos. Ya no se trata, como en el caso del saber, de formas determinadas o, como en el caso del poder, de reglas coactivas: se trata de reglas facultativas que producen la existencia como obra de arte, reglas éticas y estéticas que constituyen modos de existencia o estilos de vida (de los que incluso el suicidio forma parte). A esto llamó Nietzsche la actividad artística de la voluntad de poder, la invención de nuevas "posibilidades de vida"." 76

Si bien en el contexto de producción del rizoma, todavía no había desarrollado los modos para construir nuevas posibilidades de vida, sí es pertinente advertir que en esta época está construyendo a través de este método cierto vitalismo o una composición nueva que implique modos productivos y afirmativos de vida, y que sean medios de resistencia. Posteriormente, seguirá en esta línea de pensamiento donde se trata de afectos en composición, de deseos que pueden liberarse o estratificarse. Por ello entendemos que la perspectiva metodológica incorporada por Deleuze y Guattari, supondría la conformación de una suerte de "proyecto" ético-político a través del concepto de Cuerpo sin Órganos. En la meseta titulada “¿Cómo hacerse un Cuerpo sin Órganos?", expresa el reconocimiento al aporte ontológico, ético y político de Spinoza" ${ }^{77}$. Contra la primacía de la trascendencia o "para acabar con el juicio de Dios" $^{\text {"78 }}$ elabora el concepto que expresaría a nuestro entender el "proyecto" de un nuevo modo de pensar lo cuerpos individuales y colectivos. Implica por un lado, un campo de inmanencia del deseo entendido en términos productivos y un modo de liberación de las restricciones éticas y políticas. Puesto que el $\mathrm{CsO}$ se opone ${ }^{79}$ tanto a la organización de los órganos naturalizada que impone el organismo, a la significancia, que como ya esbozábamos a propósito de Foucault, supone el juego de una forma de expresión y una forma de contenido que implican el despotismo del significante, y a las formas de subjetivación. Sin embargo, la dosis de prudencia $^{80}$ al más fiel estilo spinosista, indica que no sería una búsqueda de liberación sin más, sino de construcción de nuevos modos de vida. Esta búsqueda, implica un hacerse a sí mismo ("cómo hacerse un $\mathrm{CsO}^{\prime}$ ), y en ese sentido entendemos el cuerpo "individual" que realiza la trasformación de su propio modo de existencia, derivando en una búsqueda ética. Asimismo, se trata de un asunto político (cuerpo colectivo) dado que para

\footnotetext{
${ }^{76}$ DELEUZE, Gilles. Conversaciones. Edición digital, p. 138

77 “Finalmente, ¿̇no sería la Ética el gran libro sobre el CsO?” Óp. Cit. DELEUZE, Gilles; GUATTARI, Félix. Mil Mesetas, p. 159. Más adelante dice: "Los drogadictos, los masoquistas, los esquizofrénicos, los amantes, todos los CsO rinden homenaje a Spinoza". Ibíd.

${ }^{78}$ Óp. cit. DELEUZE, Gilles; GUATTARI, Félix. Mil Mesetas, p. 156

79 Ídem. p. 164

80 Ídem. p. 165
} 
ENeve Ettineraxia Revista Digital de OFilosofia ISSN 1850-3578 2013 - Vol. 8 - Número VIII - Resistencia, Chaco, Argentina. Pp. 174 - 196 realizarse necesita de un Lugar, un Plan, y un Colectivo ${ }^{81}$. Es decir, se realiza en conexión con otros, en un determinado estrato (Lugar), conformando un diagrama de conexiones en esa formación social (Plan), y agenciando elementos heterogéneos (Colectivo) ${ }^{82}$. Además, sería sesgada nuestra lectura, si olvidamos que desde las primeras páginas no han cesado de determinar el procedimiento del rizoma como "como lógica de guerrillas" ${ }^{83}$ inserta en una precisa situación histórica: el capitalismo y su propagación, que "siempre es por naturaleza neocapitalismo" 84

En síntesis, la invención del rizoma como método filosófico ha encontrado nuevos matices: implica pensar desde una posición ontológica de singularidades múltiples, supone una invención del propio cuerpo, (individual/colectivo) y la trasformación ético-política de la propia existencia y de nuestros modos de pensar. Sin embargo, han quedado sin explicitar dos cuestiones. Por un lado, la relación que confinábamos entre el rizoma como método inventivo y la estética, y por otro lado, la característica del rizoma como método en contrapunto a la perspectiva tradicional. Sin pretender establecer relaciones forzadas, y a modo de hipótesis de lectura recordamos que, en el acto de creación de una obra pictórica, Deleuze advertía que es ilusoria la supuesta relación del pintor frente al lienzo en blanco. Cuando el artista se decide a pintar, tiene que luchar previamente con el caos o la catástrofe que lo acecha ${ }^{85}$. Si bien lo primero es el caos, no puede dejar que éste lo invada todo. Por el contrario, para la creación, el artista pasa por el caos o catástrofe (momento pre-pictórico), y dado que lleva en sí la historia del arte, tiene que luchar contra ella, que se presenta en la forma de clichés ${ }^{86}$. Éste, en tanto es lo naturalizado en el campo de este saber, tiene que ser destruído para crear algo nuevo. De similar manera, y salvando las distancias, consideramos que en la producción de su pensamiento, Deleuze tuvo que pasar por un momento crítico de la Historia de la Filosofía que lo acechaba (cliché), situación que respondía a costumbres de su tiempo ${ }^{87}$, para construir un método que implique la posibilidad de invención, y en este sentido, que sea un anti-método. Con la salvedad de no tomar esta instancia como momento necesario para una supuesta evolución, ni mucho menos reducir la actitud crítica a una cierta y determinada época de

\footnotetext{
81 Ídem., p. 166

82 "Un agenciamiento en su multiplicidad actúa forzosamente a la vez sobre flujos semióticos, flujos materiales y flujos sociales..." Ídem. p. 27

83 ídem, p. 22

84 Ídem, p. 24

${ }^{85}$ DELEUZE, Gilles. Pintura. El concepto de Diagrama. Buenos Aires. Cactus. 2007, p. 26

86 Ídem., p. 42

${ }^{87}$ Óp. Cit. DELEUZE, Gilles. Conversaciones, p. 8
} 
Pverea Etinexaxio Revista Digital de OFilosofla ISSN 1850-3578 2013 - Vol. 8 - Número VIII - Resistencia, Chaco, Argentina. Pp. 174 - 196

producción. Nos referimos a tendencias y problemas generales abordados en las diferentes épocas.

La singularidad del rizoma consiste, entonces, en su posibilidad inventiva, el trazado de un mapa y no la mera reproducción de sí mismo. La característica del método en el pensamiento filosófico es la de concepto conservador con los poderes que quieren reinar sobre lo múltiple, que se expresa en la construcción de imágenes de pensamiento. No obstante, el rizoma como método filosófico está en las antípodas de esta perspectiva. Recordemos a modo de ejemplo paradigmático, lo que proponía Descartes: un método capaz de aplicarlo a diversas ciencias, con la seguridad de emplear la razón en cada caso, así se expresaba:

“...aplicándolo, sentía que mi espíritu se iba acostumbrando poco a poco a concebir los objetos con mayor claridad y distinción, y que, no habiéndolo sujetado a ninguna materia particular, prometíame aplicarlo con igual fruto a las dificultades de las otras ciencias..." ${ }^{88}$

Un método que pudiese aplicarse con universalidad, puesto que el "buen sentido", es lo mejor y universalmente distribuido. La construcción del rizoma es una gran crítica a esta invención moderna y sus características son el antídoto frente a ella. De esta manera, coincidimos con J. L. Pardo, para quien la lectura de la obra deleuziana tiene que pasar por el mismo proceso que Deleuze construyó: la impresión de los movimientos del pensamiento ${ }^{89}$. Además, coincidimos en la crítica que elabora frente a las lecturas que se suelen realizar de su pensamiento, tanto las "internas" 90 , como las "externas". En particular estas últimas, se caracterizan por utilizarlo como "caja de herramientas" ${ }^{\prime 1}$, tomando prestados elementos sin previa revisión conceptual y derivando en la construcción de monstruos teóricos. Sin embargo algunas páginas de Deleuze parecen dan cabida a esta interpretación. Al respecto, recordando su relación con la historia de la filosofía y el hablar en nombre propio, nos dice Deleuze:

"Y es que hay dos maneras de leer un libro: puede considerarse como un continente que remite a un contenido, tras de lo cual es preciso buscar sus significados o incluso, si uno es más perverso o está más corrompido, partir en busca del significante. $Y$ el libro siguiente se considerará como si contuviese al anterior o estuviera contenido en él. Se comentará, se interpretará, se pedirán explicaciones, se escribirá el libro del libro, hasta el infinito. Pero hay otra manera:

\footnotetext{
${ }^{88}$ DESCARTES. René. Discurso del método. Madrid. Espasa-Calpe. 1982, p. 51

${ }^{89}$ Op. Cit. PARDO, José Luis. pp. 16-19.

90 Ídem. pp. 11-12

${ }^{91}$ Ibíd.
} 
Pverea Etinexaxio Revista Digital de OFilosofla ISSN 1850-3578 2013 - Vol. 8 - Número VIII - Resistencia, Chaco, Argentina. Pp. 174 - 196

considerar un libro como una máquina asignificante cuyo único problema es si funciona y cómo funciona, ¿cómo funciona para ti? Si no funciona, si no tiene ningún efecto, prueba a escoger otro libro. Esta otra lectura lo es en intensidad: algo pasa o no pasa. No hay nada que explicar, nada que interpretar, nada que comprender"${ }^{\prime \prime 2}$.

La aclaración metodológica que realiza a simple vista parecería que se distancia de las afirmaciones de Pardo, no obstante, desde nuestra lectura su afirmación no implica la simple y automática utilización. Por el contrario, el concepto de rizoma da cuenta de la necesidad de indagarlo para comprender su especificidad. Los principios que lo conforman invitan a subvertir el sentido de método como modelo invariable que pretende introducir lo transcendental sobre lo empírico. Esto derivaría en la reproducción de sí mismo, aunque en la repetición subsista la diferencia. Así, el carácter inventivo que hemos asumido implica tanto su matiz estético, ético, y político. Su procedimiento se centra en la experimentación y la producción de verdad, lo cual depende necesariamente de los encuentros o desencuentros que las singularidades realicen. Es decir, ante la acostumbrada manera en la que la historia y el Estado han ordenado el mundo, el libro y el pensamiento, el método propuesto conforma la inmanencia, un mundo anti jerárquico donde el "afuera" ya no es tal. Así lo expresa A. Cangi:

"La filosofía parece haber explorado la preposición sobre, con la cual se consagró a la trascendencia y la preposición bajo, para inmiscuirse en la sustancia y el sujeto. Deleuze pertenece a una larga tradición que abre la preposición entre, sustrayéndose del dentro y del fuera, para dar cuenta de las multiplicidades y sus composiciones. El entre de las interferencias es el núcleo de su pensamiento y de las variedades espacio-temporales que recrea. Ni sobre ni bajo, ni dentro ni fuera, sino a través de, entre y fuera de, en el mismo plano que abre las flexibilidades y las flexiones propias del desapego a las jerarquías ${ }^{93}$.

\section{Pensando la actualidad.}

“De los niños es el reino de Dios, se lee en el Evangelio de San Marcos, en el versículo catorce del capítulo diez. Palabras dichas para siempre y de una veracidad literal, ya que en el cielo, que es el reino de Dios, el tiempo no existe-como tampoco existe para los niños. Los niños desconocen la sucesión; habitan el liviano presente, ignoran el deber de la esperanza y la gravedad del recuerdo. Viven en la más pura actualidad, casi en la eternidad." BORGES, Jorge Luis. Obras, reseñas y traducciones inéditas. Diario Crítica 1933-1934.

\footnotetext{
92 Ídem, p. 11

93 CANGI, Adrián. Deleuze. Una introducción. Una filosofía de lo ilimitado en la naturaleza singular. Buenos Aires. Quadrata. 2011, p. 69
} 
Q Nueva Etinexaxio Revista Digital de OFilosofla ISSN 1850-3578 2013 - Vol. 8 - Número VIII - Resistencia, Chaco, Argentina. Pp. 174 - 196

Hemos intentado revisar las perspectivas metodológicas de M. Foucault y G. Deleuze en su relación con el concepto de genealogía. Hemos dado cuenta de las trasformaciones producidas en ambos pensadores y hemos intentado dilucidar las características del rizoma y su supuesta distancia con la genealogía según la interpretación foucaultiana. Sin embargo, y pese a las mínimas diferencias que encontramos entre las perspectivas metodológicas de ambos, percibimos una coincidencia ineludible entre ellos, que está imbricada en su modo de comprender la historia: la necesidad de pensar el presente. En 1983, en un texto dedicado a investigar los análisis de Kant a propósito de la historia ${ }^{94}$, Foucault advierte allí, que desde Descartes la pregunta de la filosofía concierne al presente, pero es a partir de Kant cuando la filosofía comienza a problematizar su pertenencia al presente desde la conformación de su discurso. Es decir, un discurso en el que se problematiza al filósofo en tanto intelectual, en relación con un "nosotros" del que forma parte, que es su actualidad. Un discurso además que analiza el acontecimiento mismo y su sentido, que no es otro que nuestra actualidad y nuestra existencia en ella. Asimismo años más tarde, Deleuze unto a F. Guattari, se preguntaba sobre el problema de la filosofía con la historia. En aquella oportunidad hacía explicita la coincidencia de criterio sobre la historia y su posición como filósofos. Desde sus coordenadas, nuevamente remite a quien fue una fuente de inspiración. Así lo pone de manifiesto:

\footnotetext{
"Resulta que, para Foucault, lo que cuenta es la diferencia del presente y lo actual. Lo nuevo, lo interesante, es lo actual. Lo actual no es lo que somos, sino más bien lo que devenimos, lo que estamos deviniendo, es decir el Otro, nuestro devenir-otro. El presente, por el contrario, es lo que somos y, por ello mismo, lo que estamos ya dejando de ser" ${ }^{\prime \prime 5}$.
}

Las distancias entre G. Deleuze y M. Foucault respecto a sus perspectivas metodológicas son menores, pero pueden mantener entre ellas un cierto rigor, dada la necesidad de cada pensador de hacer uso de su construcción y, tal vez, de invitarnos a experimentar con ellos la resistencia a los modos imperantes de vida e incluso seguir sus movimientos emancipatorios. Posiblemente cuando revisamos sus posiciones como intelectuales comienzan a desvanecerse las diferencias, ambos parecen haber olvidado la sucesión del tiempo, para habitar y alivianar el presente.

\footnotetext{
${ }^{94}$ FOUCAULT, Michel. ¿Qué es la llustración? Madrid. Ediciones de la Piqueta. 1996.

${ }^{95}$ DELEUZE, Gilles; GUATTARI, Félix. ¿Qué es la filosofía? Barcelona. Anagrama. 1993, p. 114
} 